\title{
The Cytology of Benign, Pseudomalignant Reactive Changes in Fibrous Tissue, Adipose Tissue and Striated Muscle in Fine Needle Aspiration Samples
}

One reason for a false-positive diagnosis of sarcoma in a soft tissue tumour aspirate is the misinterpretation of benign, reactive cellular changes in benign conditions.

\section{Fibrous Tissue}

Normal fibroblasts/myofibroblasts appear in FNA samples as spindle-shaped cells with slender cytoplasm, often with elongated cytoplasmic processes. The nuclei are rounded, ovoid or fusiform with regular chromatin and small nucleoli, if any. The cells are seen either as dissociated or in small clusters or runs of loosely attached cells. Stripped nuclei are not uncommon (fig. 8).

Reactive fibroblasts/myofibroblasts show, irrespective of cause, a wide variation in size and shape. The cells become polyhedral or triangular, often with rather abundant cytoplasm. They may show angulated cytoplasmic extensions or cytoplasmic

Fig. 8. Normal fibroblasts in an FNA biopsy. A run of loosely cohesive cells with ovoid, uniform nuclei, regular chromatin and bipolar cytoplasm. MGG. Medium magnification.

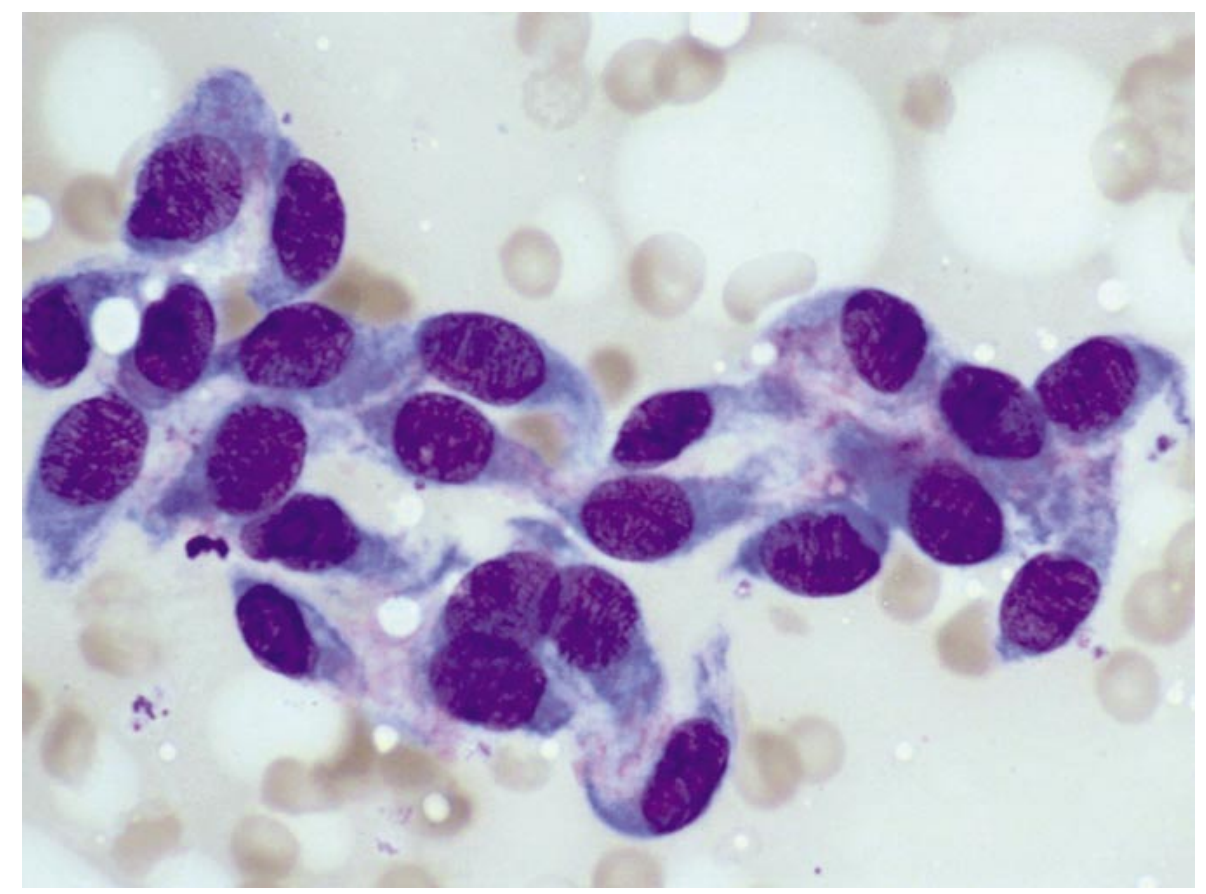




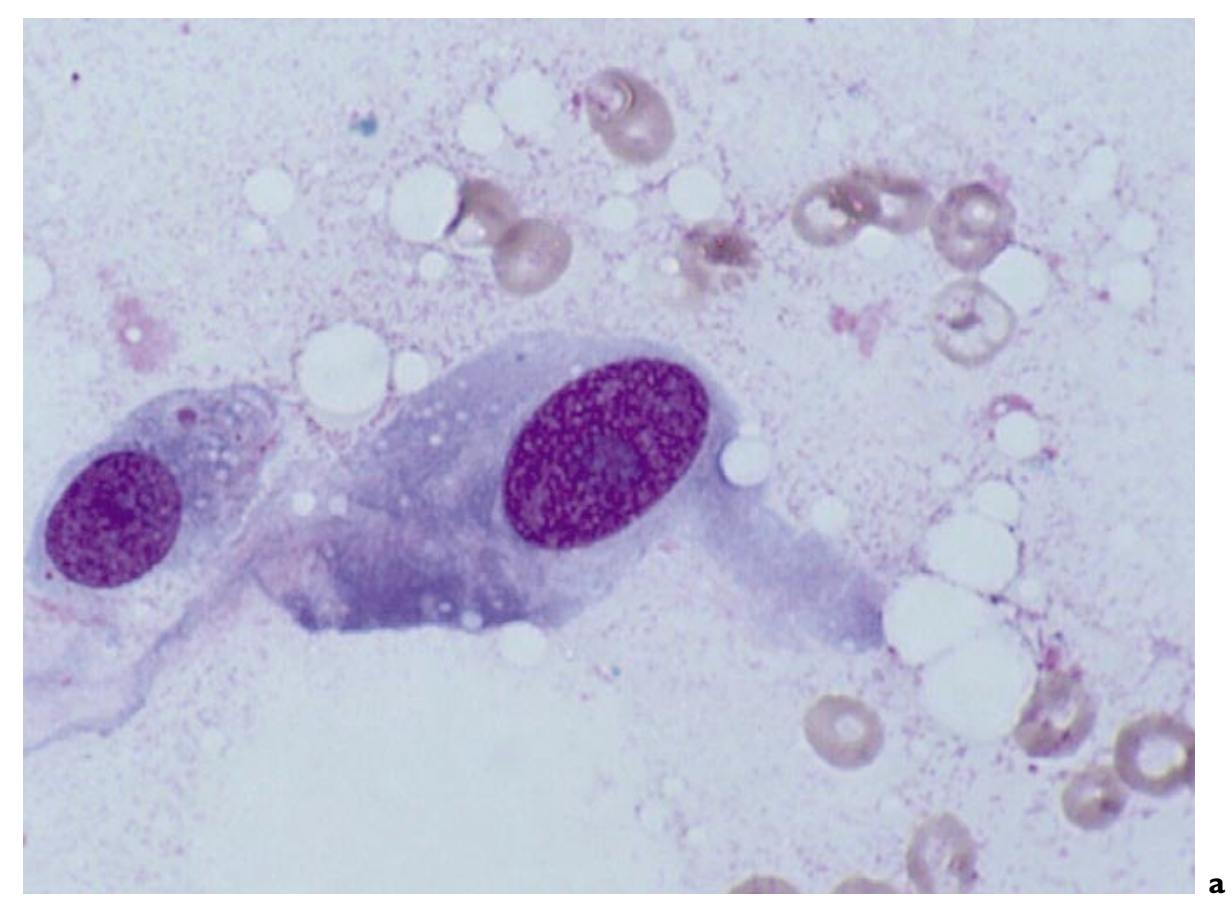

Fig. 9. Example of reactive fibroblast/myofibroblast. a Larger than normal fibroblasts with more abundant cytoplasm with angulated extensions and large nuclei with prominent nucleoli. b A multinucleated, ganglioncell-like reactive fibroblast. MGG. High magnification.

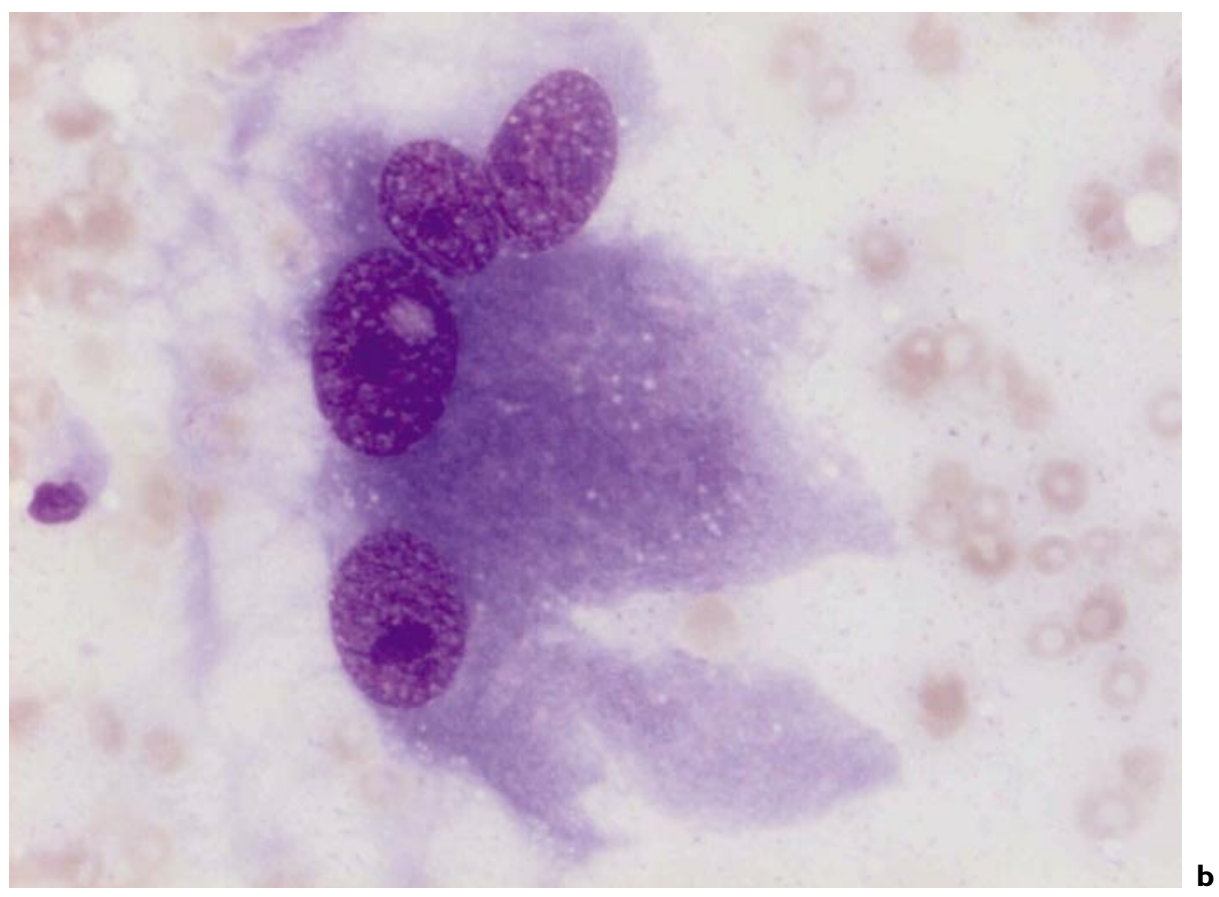

processes. The nuclei vary in size and shape (rounded, ovoid, spindle-shaped) and nucleoli may be large and prominent. Binucleated cells are not uncommon (fig. 9a, b).

Typical examples of the pleomorphic appearance of reactive fibroblasts/myofibroblasts are seen in the pseudomalignant, benign soft tissue lesions, especially in nodular fasciitis and proliferative myositis.

\section{Adipose Tissue}

Normal adipose tissue is seen as small fragments or clusters of large cells with abundant univacuolated cytoplasm and small, dark, regular nuclei. A discrete network of thin capillaries is often observed. Dissociated adipocytes are uncommon. 


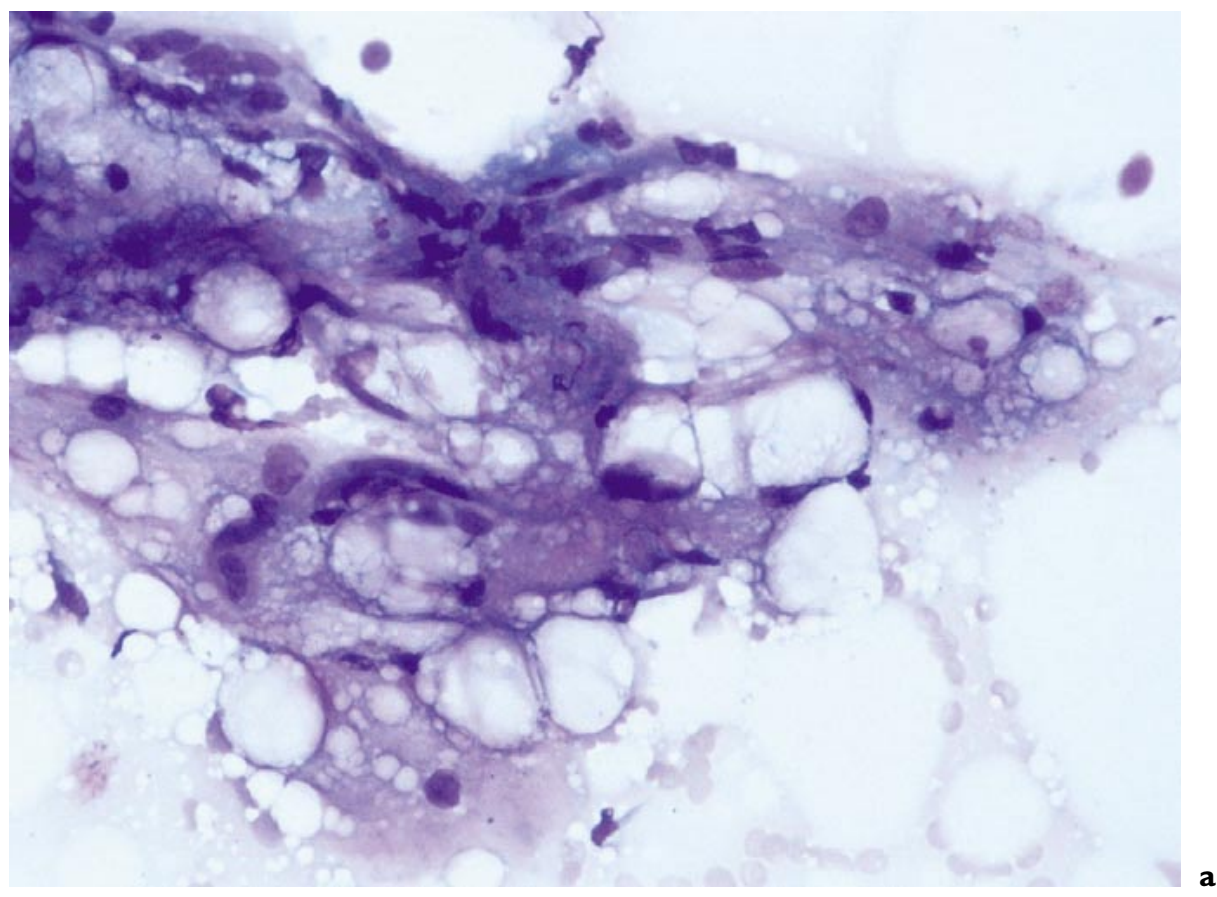

Fig. 10. Cellular changes in adipose tissue. a Partly myxoid background and differentsized adipocytes. b Increased cellularity due to the presence of fibroblasts and histiocytes. a, b MGG. Medium magnification.

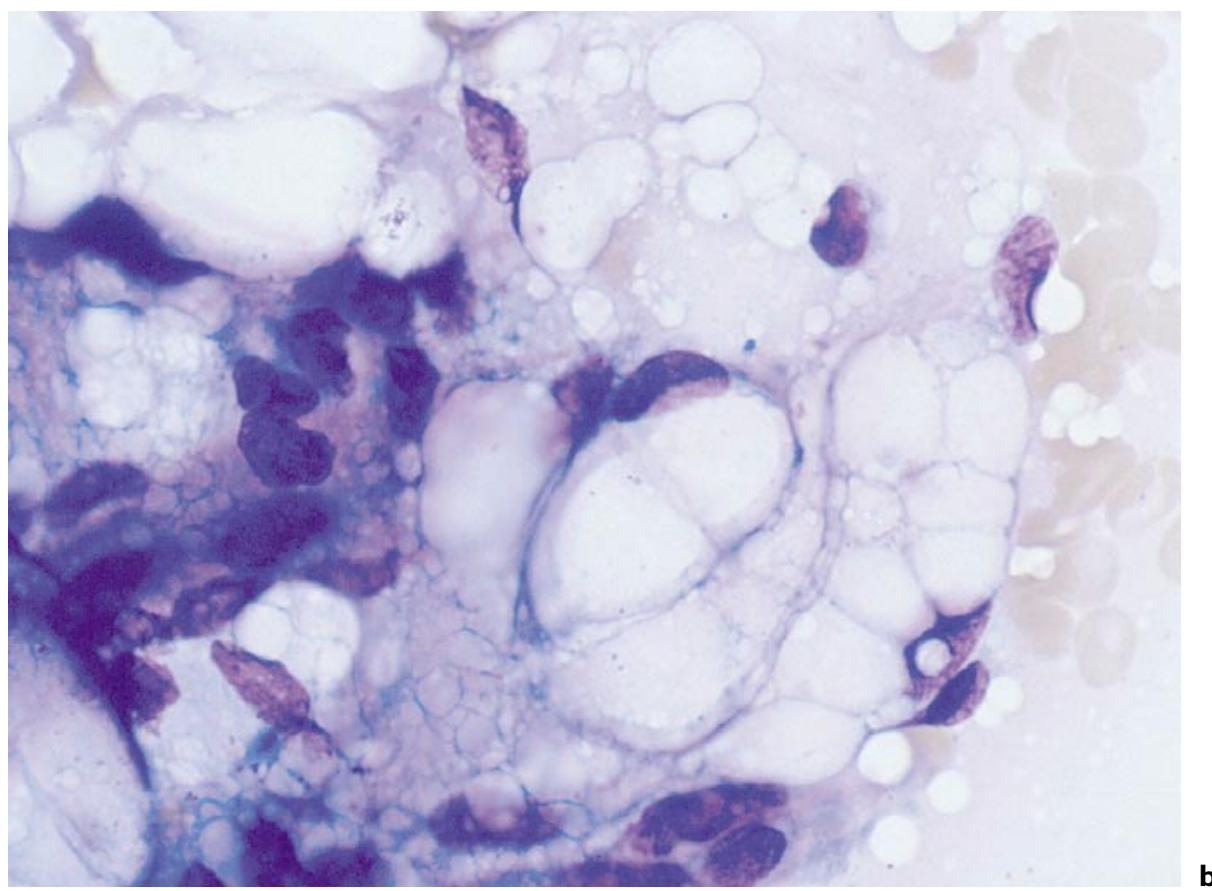

In reactive states, posttraumatic, inflammatory or in adipose tissue bordering various tumours, the adipose tissue may exhibit a myxoid-like background, the capillary network is more pronounced, the adipocytes vary in size and the fat fragments appear more cellular than normal due to the presence of fibroblasts and histiocytes (fig. 10a, b). Histiocytes with foamy or vacuolated cytoplasm appear between the fat fragments.

\section{Striated Muscle}

Normal striated muscle in FNA samples is seen as fragments of muscle fibres with small dark nuclei and a more or less evident striation. The fibres are densely eosinophilic in HE and dark blue in MGG. Regenerating muscle fibres appear in FNA samples as multinucleated cells of varying 


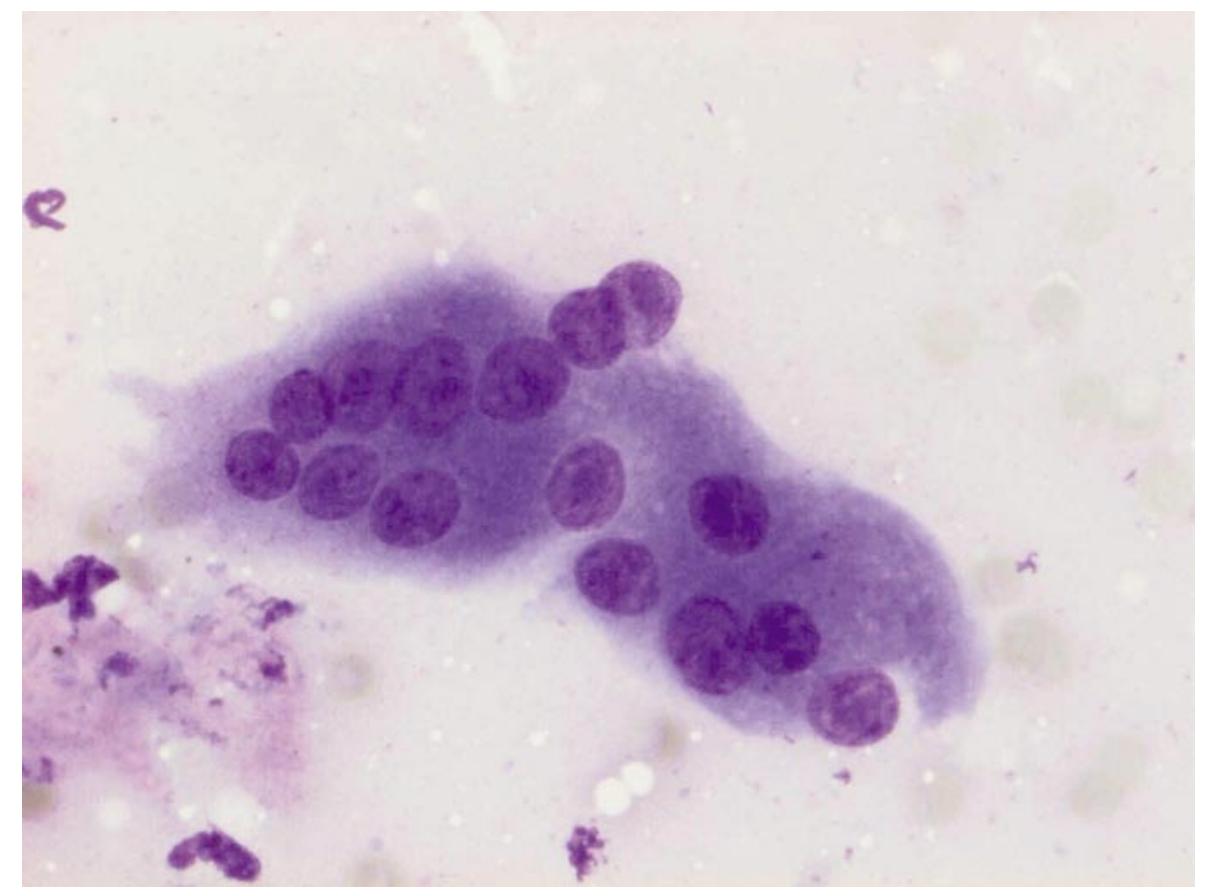

Fig. 11. Examples of regenerating striated muscle fibres. a Typical 'muscle giant cells' with rows of nuclei and dark blue cytoplasm. MGG. High magnification. b The cytoplasm is eosinophilic in HE. High magnification.

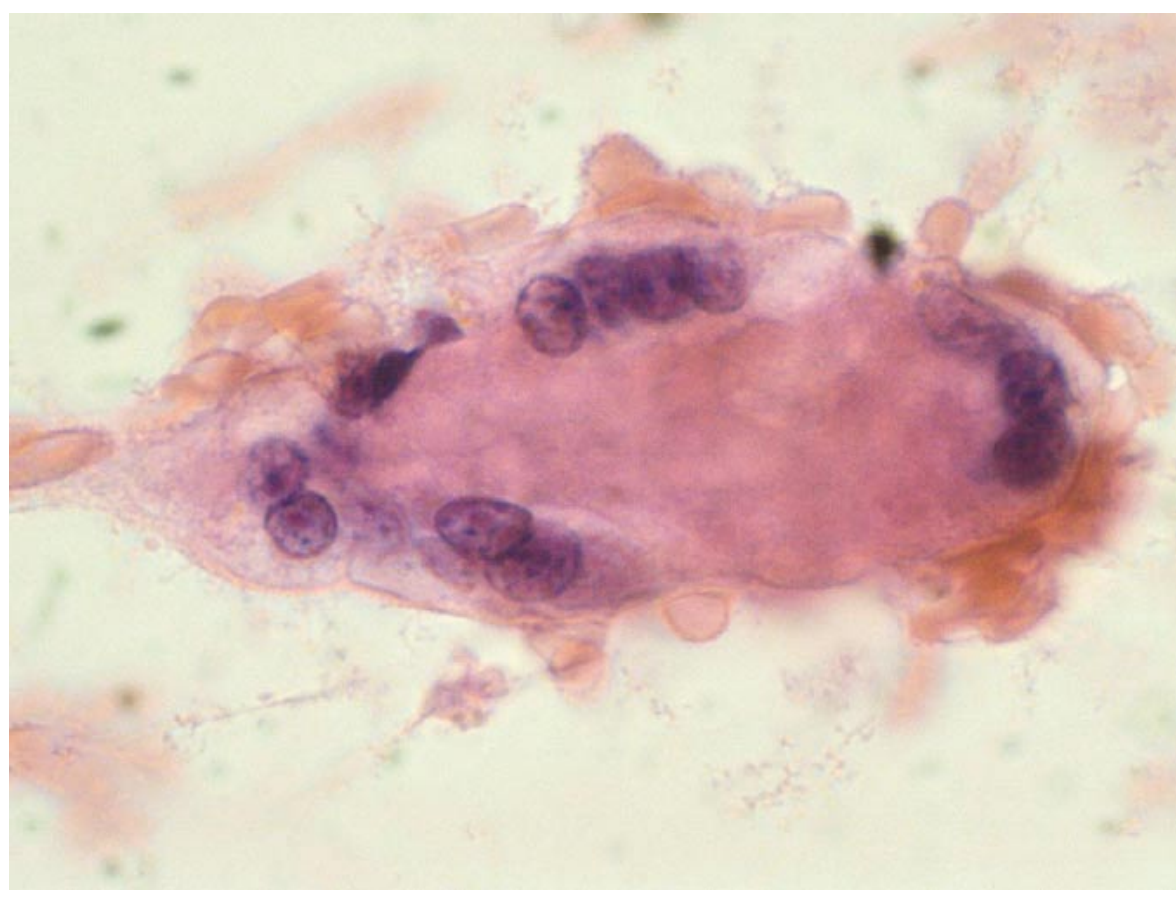

size and shape. They are rounded, polyhedral, strap-shaped or tadpole-like. The cytoplasm is densely eosinophilic in HE and dark blue in MGG. The multiple nuclei are moderately large, uniform in size and often harbour a prominent nucleolus. The nuclei are typically arranged in rows, eccentrically located (fig. 11a-c). 
Fig. 11c. A uninuclear, tadpole-like regenerating striated muscle fibre. MGG. High magnification.

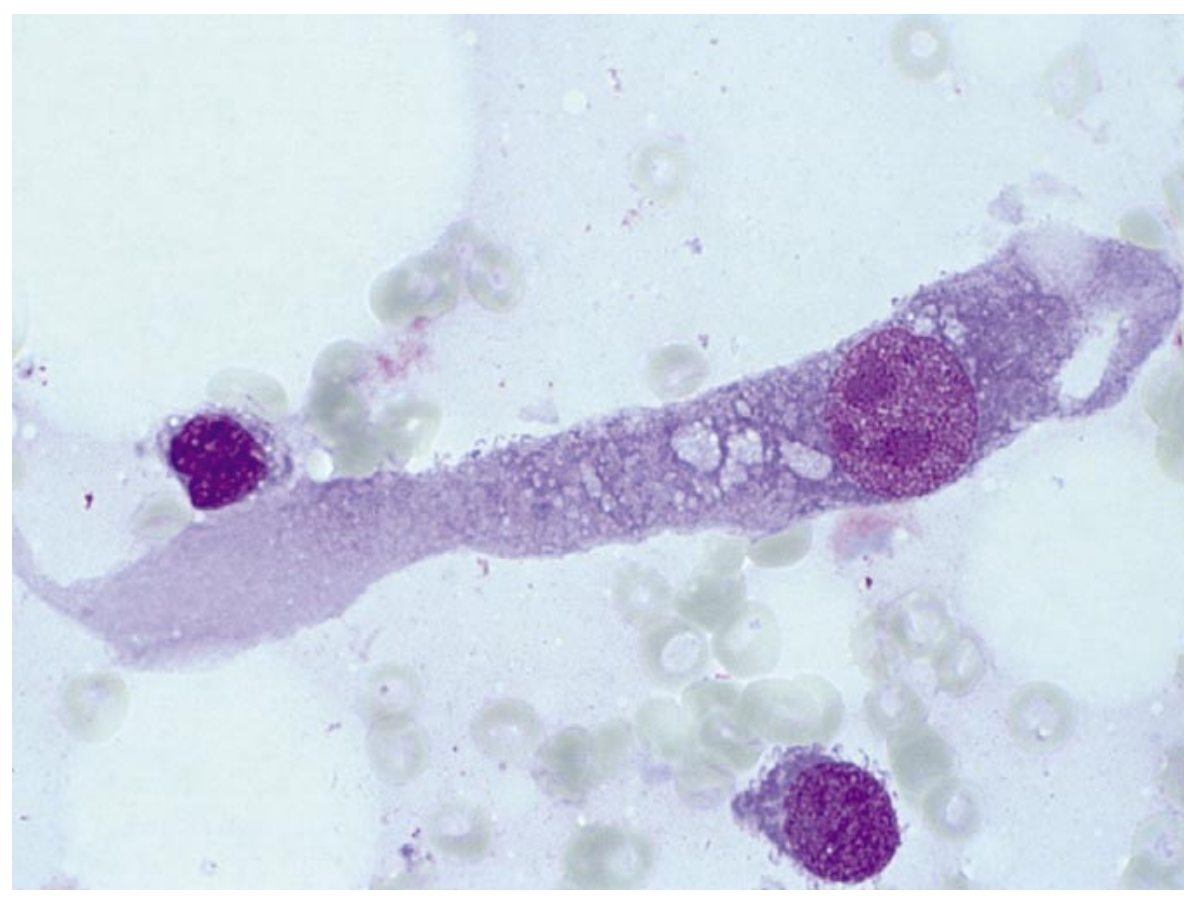

Table 4. A summary of benign 'pseudomalignant changes' in aspirated material from fibrous and adipose tissue and striated muscle

\begin{tabular}{|c|c|c|}
\hline Tissue & Cellular changes & Lesions \\
\hline Fibroblasts/myofibroblasts & $\begin{array}{l}\text { Variation in size, variation in shape; elongated, } \\
\text { triangular, polygonal, plump with cytoplasmic } \\
\text { extensions; variable nuclear shape and size; } \\
\text { binucleation; prominent nucleoli }\end{array}$ & $\begin{array}{l}\text { Benign pseudosarcomatous soft tissue lesions } \\
\text { Posttraumatic states }\end{array}$ \\
\hline Adipose tissue & $\begin{array}{l}\text { Increased vascularity; increased cellularity } \\
\text { (fibroblasts, endothelial cells, histiocytes); } \\
\text { multivacuolated cytoplasm in adipocytes; uni- or } \\
\text { multinucleated histocytes between fat fragments } \\
\text { (lipophages) }\end{array}$ & $\begin{array}{l}\text { Status after fat necrosis } \\
\text { Posttraumatic states } \\
\text { Adipose tissue surrounding various } \\
\text { non-adipose tumours }\end{array}$ \\
\hline Striated muscle & $\begin{array}{l}\text { Multi- or uninucleated regenerating muscle fibres } \\
\text { ('muscle giant cells'); occasionally presence of } \\
\text { tadpole-like regenerating muscle fibres; prominent; } \\
\text { nucleoli; dense eosinophilic (HE) or dark blue } \\
\text { (MGG) cytoplasm }\end{array}$ & $\begin{array}{l}\text { Aspirates from tumours/lesions infiltrating } \\
\text { striated muscle } \\
\text { Examples: intramuscular lipoma, intramuscular } \\
\text { myxoma, desmoid, fibromatosis colli }\end{array}$ \\
\hline
\end{tabular}

Regenerating muscle fibres are mainly found within FNA samples from tumours infiltrating striated muscle. Typical examples are infantile fibromatosis colli and desmoid fibromatosis.
A summary of the reactive cytological changes in fibrous tissue, adipose tissue and striated muscle is presented in table 4 . 